\title{
BRADYCARDIA WITH CAROTID SYSTEM INFUSIONS OF COLD BLOOD DURING ENDARTERECTOMY*
}

\author{
Roger L. Walker, M.D., Ch.B., Richard M. Schlobohm, M.D., \\ Francis N. Cooke, M.D., M.S., ANd W. Dean Warken, M.D. $†$
}

RECENT STUdies have shown that of almost five thousand patients with signs of ischaemic cerebral vascular disease, at least sixty per cent had surgically correctible vascular lesions. ${ }^{1}$ Surgeons have been able to relieve the obstruction and restore vascular patency since $19544^{2,3}$

One of their concerns has been the effect of the period of cerebral ischaemia attendant upon temporary complete occlusion of the internal carotid artery during thrombendarterectomy. ${ }^{4}$ Cooke $^{5}$ described a technique of local cerebral hypothermia which has been in use at this institution. This communication reports some changes in the electrocardiogram and the pulse rate which have occurred at the initiation of regional cerebral hypothermia in a series of seven cases.

\section{Procedure}

Patients were premedicated with pentobarbital $100 \mathrm{mg}$ and atropine $0.6 \mathrm{mg}$. After preoxygenation, anaesthesia was induced with thiopental, and endotracheal intubation was performed with the aid of succinylcholine. Anaesthesia was maintained with halothane and oxygen. Five hundred millilitres of blood were withdrawn from a femoral artery, heparinized, mixed with $100 \mathrm{ml}$ of lactated Ringer's solution, and then cooled in an ice-water bath. During the arteriotomy, blood volume was maintained by intravenous infusion of 0.6 per cent Dextran or whole blood. Throughout the period of carotid occlusion the $\mathrm{Pa}_{\mathrm{CO}_{2}}$ was maintained between 45 and $55 \mathrm{~mm} \mathrm{Hg}$, and care was taken to maintain the systemic pressure at or slightly above awake levels. A lead 2 electrocardiogram was recorded throughout the procedure.

When the carotid arteries had been dissected free, the cooled arterial blood (about $10^{\circ} \mathrm{C}$ ) was infused at a rate of $100 \mathrm{ml} / \mathrm{min}$ into the distal internal carotid artery. The thrombendarterectomy was then begun in the isolated arterial segment.

Bradycardia was observed immediately following infusion of cold arterial blood in each of seven patients (Fig. 1). It may be seen that in each case the heart rate slowed within ten seconds of the beginning of the infusion. Patients 3,6 , and 7 received atropine $0.4 \mathrm{mg}$ intravenously during the 30 minutes before

"This investigation was supported in part by NIH Training Grant no. T12-GMO1835-01 from the National Institute of General Medical Sciences.

fFrom the Departments of Anesthesiology and Surgery, University of Miami School of Medicine and Jackson Memorial Hospital, Miami, Florida. Dr. Walker is currently in the Department of Anaesthesia, Mercy Hospital, Miami, Florida. Reprint requests may be sent to: P.O. Box 875, Biscayne Annex, Miami, Florida 33152 (Dr. Schlobohm). 


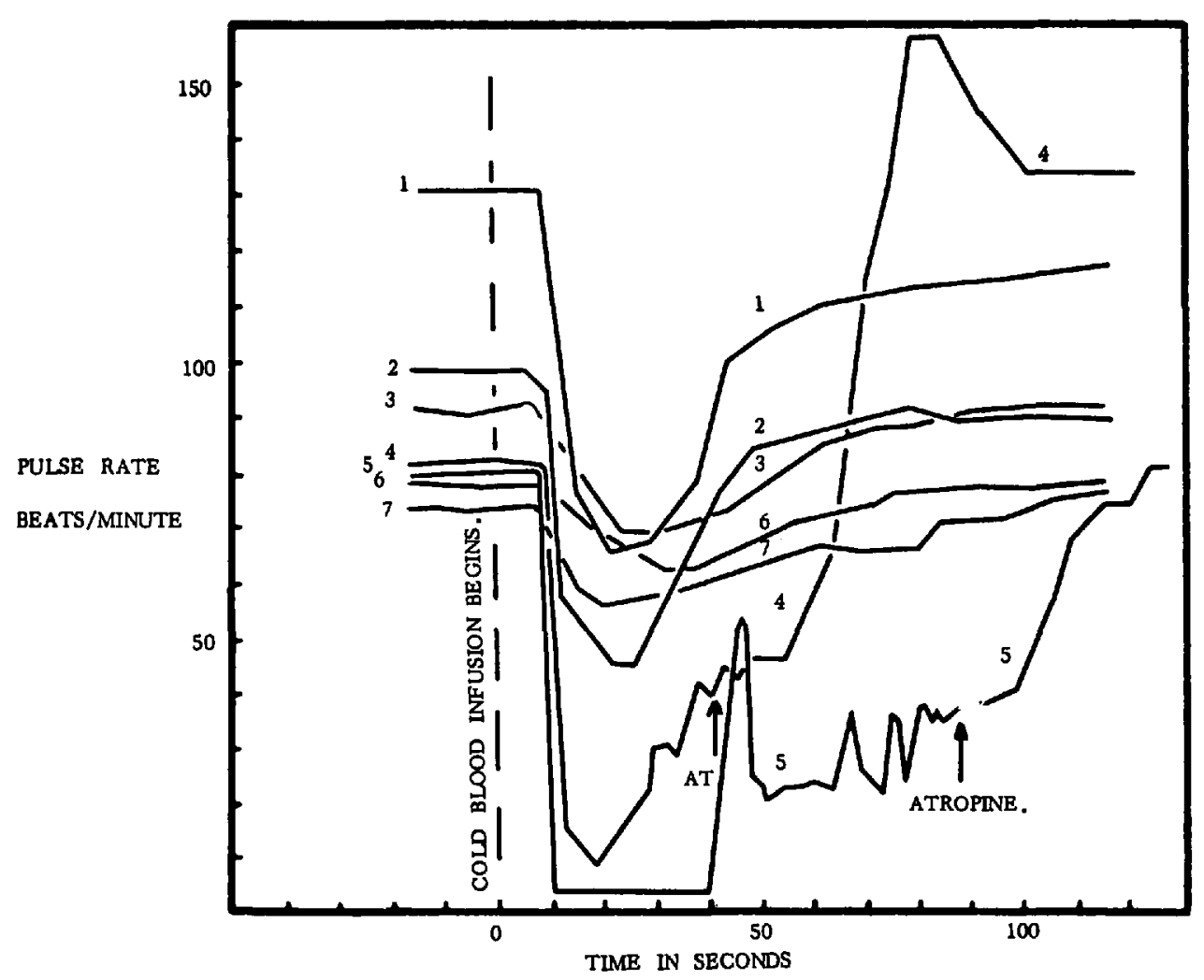

FIGURE 1. Heart rate changes during ipsilateral carotid system infusions of cold arterial blood. The heart rate dropped to $0-80$ per cent of initial rates. Fall in heart rate was least ( $76-80$ per cent) in patients 3,6 , and 7 , each of whom had received atropine prior to the infusion.

the infusion, and patients 4 and 5 received atropine $0.4 \mathrm{mg}$ at the points indicated by the arrow.

The most profound bradycardia was observed in patients four and five.

Patient number four was a 62-year-old male who had experienced transient episodes of blindness. A preoperative electrocardiogram had revealed an intraatrial conduction block. His blood pressure was 128/86, and clinical examination of his heart and lungs did not reveal any abnormality. Eight seconds after the beginning of the infusion of the cold blood (Fig. 2) indicated by the arrow, there was a sudden bradycardia, beginning with a four-second period of asystole, and the P-R interval was prolonged from 0.12 to 0.22 seconds. There was then a period of 6.4 seconds before the next ventricular systole. The heart rate then increased spontaneously, some of the beats being nodal in origin. Atropine $0.4 \mathrm{mg}$ intravenously immediately corrected the bradycardia. The patient had a normal awakening and a satisfactory postoperative course.

Patient number five was a 61-year-old female who had experienced transient attacks of cerebral ischaemia. An arteriogram revealed stenosis of the right internal carotid artery. Preoperatively her blood pressure was 160/80. Pulse rate was 86 per minute and regular. A soft grade I-II systolic murmur was heard over the pulmonic area. Figure 3 is the continuous electrocardiogram recorded from 

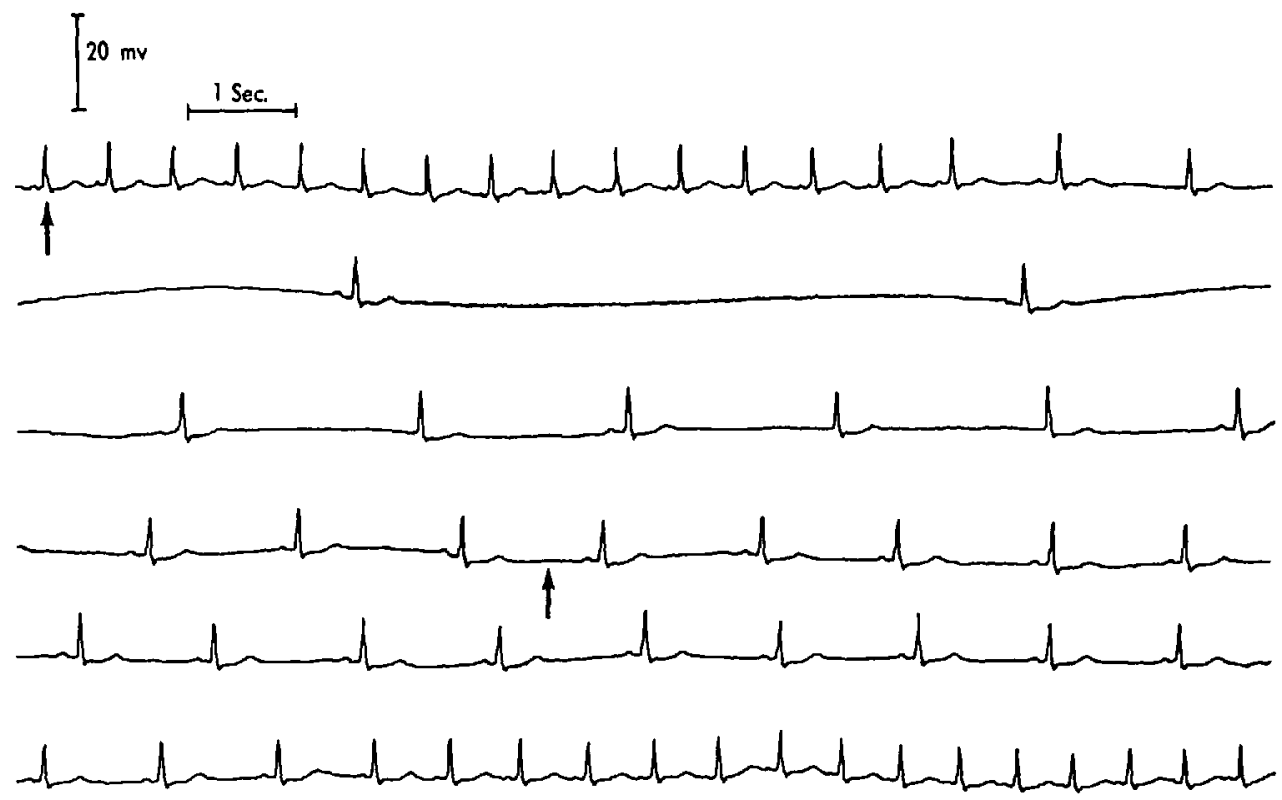

Frgure 2. Continuous lead 2 ecc during ipsilateral carotid system infusions of cold arterial blood in patient 4 . Infusion begins as indicated by the first arrow. Intravenous atropine $0.4 \mathrm{mg}$ was given 40 seconds after infusion began (second arrow). Heart rate increased to initial level within 25 seconds.
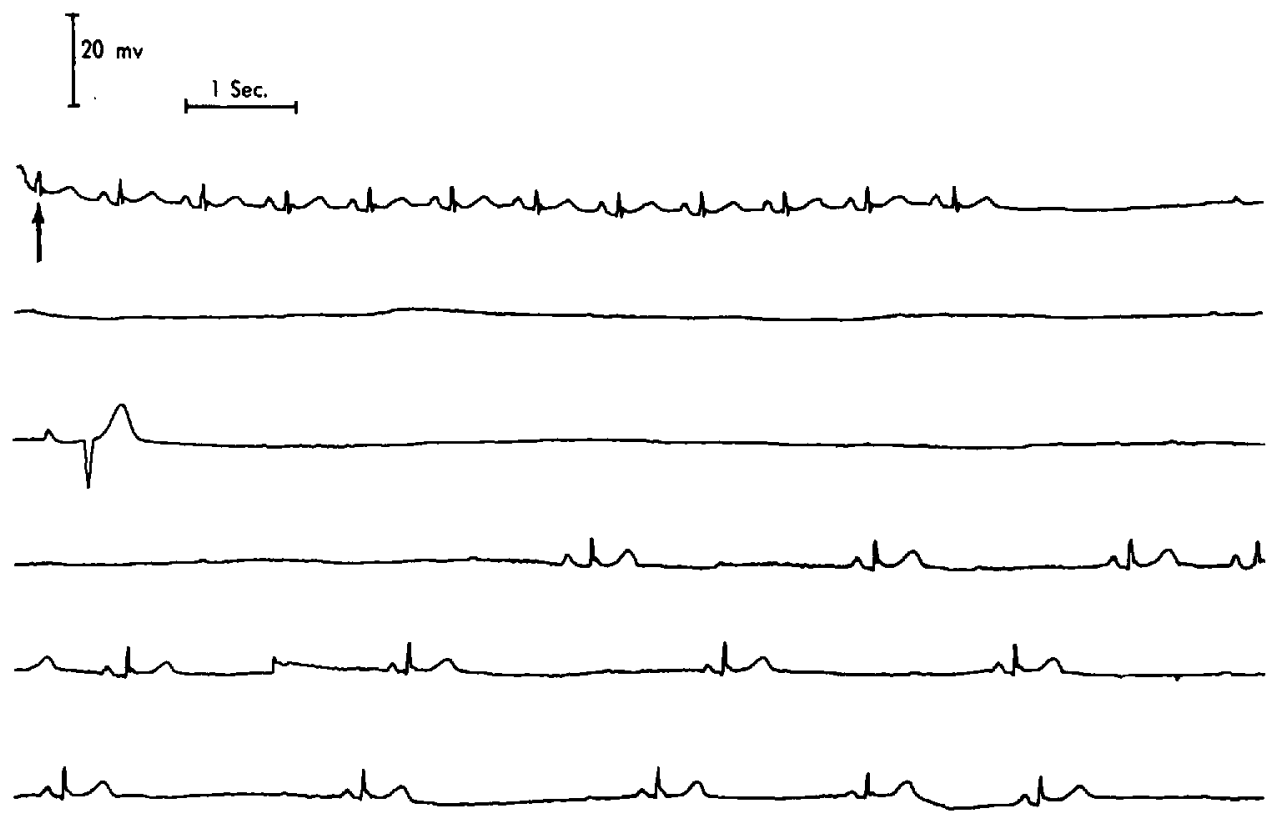

Figure 3. Continuous lead 2 EcG during ipsilateral carotid system infusions of cold arterial blood in patient 5 . Start of infusion is indicated by the arrow. Intravenous atropine $0.4 \mathrm{mg}$ was given 18 seconds after the tracings in this figure. Heart rate returned to initial level 36 seconds later. 
the beginning of the infusion of cold arterial blood into the right internal carotid artery. Asystole occurred 8.5 seconds after the beginning of the infusion and lasted 15 seconds. This was followed by an abnormal QRS complex with a normal $P$ wave, a P-R interval of 0.4 seconds, and an ectopic ventricular beat. Then a second period of ventricular asystole of 16 seconds during which there were five small $P$ waves. The heart rate then increased spontaneously and the P-R interval shortened before intravenous atropine could take effect. The patient awoke normally from anaesthesia with good carotid pulses, speaking clearly and moving all four limbs.

Right carotid endarterectomies were performed in patients 2, 3, 5, and 6 . The left side was involved in 1, 4, and 7 . Whether cold blood was infused into the right or the left internal carotid artery did not appear to make appreciable difference in the occurrence of bradycardia.

\section{Discussion}

One method of protection against cerebral ischaemia has been to increase collateral blood flow by increasing $\mathrm{Pa}_{\mathrm{CO}_{2}} ;{ }^{6}$ however, this method becomes less efficacious in the presence of advanced cerebrovascular disease. ${ }^{7}$ The more direct approach is to use hypothermia to reduce cerebral metabolic oxygen consumption of that area perfused by the vessel being operated upon.

It has been demonstrated in dogs that cerebral oxygen consumption can be reduced by 7.3 per cent for each centigrade degree fall in temperature. ${ }^{8}$ Total body hypothermia has been used, ${ }^{4}$ but requires a large amount of preparation and will more widely alter total body physiology. Although regional hypothermia of the brain by extracorporeal pump cooling units has been reported, ${ }^{9}$ this technique also requires extensive preparations. Hemispheric temperature changes produced by Cooke's method ${ }^{5}$ of total hypothermia have been documented for dogs. ${ }^{10}$ On perfusion of the internal carotid artery with $400-500 \mathrm{ml}$ of $4^{\circ} \mathrm{C}$ arterial blood for 8.7 minutes, the temperature on the perfused side decreased by $11.8^{\circ}$ and that of the opposite hemisphere by $5.1^{\circ} \mathrm{C}$. No changes in the electrocardiogram were reported, except those consistent with moderate hypothermia.

\section{Aetiology of observed bradycardia}

It is unlikely that there would be any appreciable cooling of the cerebral venous blood in the first 8-10 seconds, and any myocardial temperature change would be even further delayed by dilution. We would thus exclude any direct myocardial origin of this bradycardia.

Alterations of cardiovascular status often involve reflex mechanisms. The profound bradycardia could be related to the occurrence of a sudden increase in vagal tone to the heart. The evidence supporting this hypothesis is the sudden disappearance of the $P$ waves, indicating acute sinus nodal depression, and a prolongation of the P-R interval, suggesting a depression of the A-V node. Furthermore, the bradycardia appeared to resolve with the vagal blockade effect of intravenous atropine administration. 
The afferent origin(s) of this apparent increase in vagal tone and consequent bradycardia could have been caused by several factors: (a) A sudden distension of the carotid sinus by the infusion of blood, or by the surgical manipulation itself. This is unlikely, as the infusion was distal to the isolated carotid sinus, which was denervated by the surgical dissection and the local infiltration of lidocaine. $(b)$ A sudden distention of another, unknown, pressure receptor system located distal to the carotid sinus yet within the internal carotid system. The delay of 8-10 seconds before the onset of the bradycardia is longer than the delay associated with a pressure-receptor system, carotid sinus or otherwise, which may be as short as 1.4 seconds. ${ }^{11}$ (c) An increase in intracranial pressure is known to cause a rise in systemic blood pressure, and there may be an associated bradycardia. ${ }^{12,13}$ The postulated mechanism is ischaemia of the medullary centres. It is unlikely that an increase in intracranial pressure was responsible for this bradycardia, as only a small quantity of blood had been infused at a relatively slow rate $(100 \mathrm{ml} / \mathrm{min})$ with no outflow occlusion. $(d)$ The possibility remains that the observed bradycardia was initiated by the sudden exposure to cold of a part of the central nervous system supplied by the internal carotid artery. Such an area is the hypothalamus. Although the medulla oblongata contains the primary integrative site for cardiovascular reflexes (vasomotor centre), it is perfused by the vertebral arteries. The supramedullary centres such as the hypothalamus are considered to be secondary, but do have significant influence on the vasomotor centre.

It has been shown in man that both electrical ${ }^{14}$ and mechanical ${ }^{15}$ stimulation of the hypothalamus may cause a slowing of the heart rate. The results of animal experiments are confusing. Hockman ${ }^{16}$ showed that stimulation of the diencephalon and mesencephalon caused ectopic ventricular rhythms which were unaffected by vagotomy but were prevented by large doses of propranolol. One of the difficulties in associating supramedullary action with the bradycardia observed in our cases arises from observations that these actions in animals are typically cardiotonic instead of cardioplegic. ${ }^{17,18}$ However, if a sudden large negative heat gradient were to suppress net sympathetic tone from the hypothalamus through the vasomotor centre, the observed bradycardia could be the result of a momentary relative dominance of vagal tone.

Whatever the aetiological mechanism, if the bradycardia is mediated by a sudden increase in vagal tone it may be prudent to add an intravenous dose of 0.4-1.2 mg atropine prior to initiation of cold blood infusion into the carotid system.

\section{SUMMariY}

A method of local cerebral hypothermia has been used over the past nine years to mitigate the effects of cerebral ischaemia during carotid endarterectomy. Bradycardia, seen immediately after initiation of a $500 \mathrm{cc}$ infusion of cold blood in the carotid artery, has been quite transient in duration. Atrio-ventricular conduction is prolonged, and periods of 15 seconds of asystole have been recorded. It would appear that the bradycardia is related to a sudden cerebral cold stimulus to the hypothalamus. 


\section{RÉSUMÉ}

Au cours des neuf dernières années, nous avons employé une méthode d'hypothermie cérébrale locale pour atténuer les effets de l'ischémie cérébrale au cours de l'endartériectomie carotidienne. Dès le début de l'infusion de $500 \mathrm{cc}$ de sang froid dans l'artère carotidienne, il est apparu une bradycardie qui, toutefois, n'a été que transitoire. La conduction atrio-ventriculaire est ralentie et nous avons observé des périodes d'asystolie de 15 secondes. Selon toute apparence, le bradycardie est attribuable à une stimulation cérébrale soudaine par le froid au niveau de l'hypothalamus.

\section{REFERENCES}

1. Fields, W. S.; North, R. R.; Haas, W. K.; Galbraith, J. G.; Wylie, E. J.; Ratinov, G.; Burns, M. H.; MacDonald, M. C.; \& Mayer, J. S. Joint Study of Extracranial Arterial Occlusion as a Cause of Stroke. J.A.M.A. 203: 955 (1968).

2. Eastcott, H. H. G.; Pickering, G. W.; \& RoB, C. G. Reconstruction of Internal Carotid Artery in a Patient with Intermittent Attacks of Hemiplegia. Lancet. 2: 944 (1954).

3. Coolex, D. A.; Al-Naaman, Y. D.; \& Cafton, C. A. Surgical Treatment of Arteriosclerotic Occlusion of Common Carotid Artery. J. Neurosurg. 13: 500 (1956).

4. Ferder, D. A. Moderate Hypothermia in Extracranial Carotid Artery Surgery. Minnesota Med. 48: 594 (1965).

5. Cooke, F. N. Internal Carotid Artery Occlusion: Surgical Management with Regional Hypothermia. J. Florida M.A. 47: 781 (1961).

6. Wells, B. A.; Keats, A. S.; \& Cooley, D. A. Increased Tolerance to Cerebral Ischemia Produced by General Anesthesia during Temporary Carotid Occlusion. Surgery. 54: 216 (1963).

7. Chaythorne, N. W. B. \& Bloor, B. M. Anesthetic Management for Carotid Endarterectomy. Anesth. \& Anal. 46: 589 (1967).

8. Rosomoff, H. L. \& Holaday, D. A. Cerebral Blood Flow and Cerebral Oxygen Consumption during Hypothermia. Am. J. Physiol. 179: 85 (1954).

9. Dickinson, P. H.; Hankinson, J.; \& Marshal., M. Internal Carotid Artery Stenosis. Brit. J. Surg. 51: 703 (1964).

10. Sundt, T. M.; Nofzinger, J. D.; \& Murphy, F. Hypothermic Cerebral Perfusion with Non-heparinized Blood: Experimental techniques. Am. Surgeon. 32: 131 (1966).

11. Dauber, D.; Landowne, M.; Katz, L. M.; \& Weinberg, H. Effects of Interrupting and Restoring the Circulation to the Lower Extremities. J. Clin. Invest. 21: 47 (1942).

12. Cushing, H. Concerning a Definite Regulatory Mechanism of the Vasomotor Center Which Controls Blood Pressure during Cerebral Compression. Bull, Johns-Hopkins Hospital. 12: 290 (1901).

13. Gurton, A. C. Acute Hypertension in Dogs with Cerebral Ischemia. Am. J. Physiol. 154: $45(1948)$.

14. White, J. C. Autonomic Discharge from Stimulation of the Hypothalamus in Man. Assoc. Res. Nerv. Ment. Dis. 20: 854 (1940).

15. Pool, J. L. \& Kesslen, L. A. Mechanism and Control of Centrally Induced Cardiac Irregularities during Hypothermia. J. Neuro. Surg. 15: 52 (1958).

16. Hockman, C. H.; MaucK, H. P.; \& Hoff, E. C. Electrocardiogram Changes Resulting from Cerebral Stimulation: A Spectrum of Ventricular Arrhythmias of Sympathetic Origin. Am. Heart J. 71: 695 ( 1966 ).

17. Mannivg, J. W. Intracranial Representation of Cardiac Innervation. In W. C. Randall (ed.), Nervous Control of the Heart. Baltimore: Williams \& Wilkins (1965).

18. Perss, C. N. Concepts of Cardiovascular Regulation. In W. C. Randall (ed.), Nervous Control of the Heart. Baltimore: Williams \& Wilkins (1965). 